DOI: 10.17117/na.2016.11.01.321

Поступила (Received): 15.11.2016

\title{
Уринбаева Ю.П.
}

\section{Перспективы повышения уровня жизни населения на основе развития малого и частного бизнеса}

\author{
Urinbayeva Yu.P. \\ Prospects for raising living standards through the \\ development of small and private business
}

В статье обосновывается особая значимость повышения уровня жизни населения на основе развития малого и частного бизнеса выявляются факторы, сдерживающие активное внедрение и повышения уровня жизни населения, указываются возможные пути решения назревших проблем в данной сфере

Ключевые слова: услуга, сервис, сфера услуг, уровень жизни населения, качество жизни, потребности, потребление, издержки потребления

Уринбаева Юлдуз Пирназаровна

Аспирант

Самаркандский институт экономики и сервиса г. Узбекистан

\begin{abstract}
The article explains the special importance of raising living standards through the development of small and private businesses to identify the factors hindering the implementation of active and improve shiny population, the possible ways to solve pressing problems in this area
\end{abstract}

Key words: service, service sphere: level being of population, quality of being, the high quality level of being, factors, prosperity, and depositions of population

\author{
Urinbayeva Yulduz Pirnazarovna \\ Graduate \\ Samarkand institute of economy and service \\ Uzbekistan
}

Исключительно важный и ответственный период переживает ныне наша страна. Во всех сферах её жизни всё большую силу приобретают важные процессы модернизации общества, технического и технологического обновления производства, формирования цивилизованных, подлинно рыночных отношений. Конечная цель преобразований в сфере экономики глубокое обновление всей системы экономических отношений с учётом достижений мирового опыта и создание на этой основе процветающей, инновационной экономики, которая и должна обеспечить достойную жизнь многомиллионному населению Республики Узбекистан. Однако для успешного достижения поставленных целей и задач предстоит ещё немало приложить сил как в плане выработки кардинальных решений относительно выбора путей, так и тактики и стратегии экономического развития, настойчиво добиваясь воплощения принятых решений в нашу действительность. Промежуток времени, который необходим для реконструкции плановой системы и формирования взамен социально ориентированной 
рыночной экономики, во многом определяется становлением и эффективностью функционирования малого и частного бизнеса, который за все годы самостоятельного развития не случайно стал предметом всеобщей заботы и внимания.

Современная жизнь ставит на повестку дня ещё много, непростых вопросов, умелое решение которых способствовало бы созданию желаемой, социально ориентированной рыночной экономики кратчайшим путем, как можно быстрее и с наименьшими затратами. Среди механизмов, создающих предпосылки для реализации намеченных государством программ экономических реформ с целью перехода к цивилизованной рыночной экономике, важное место занимает малый и средний бизнес. Новизна и неординарность решаемых в этой сфере проблем требуют особого, более тщательного подхода к принятию решений, к совершенствованию правовых основ малого и частного бизнеса, к системе налогообложения её субъектов и т.д.

О необходимости и значении развития малого и частного бизнеса в Узбекистане, о той роли, которая отводится ему в государственной экономической политике, свидетельствует тот факт, что задачи его развития специально обсуждались на сессии Олий Мажлиса и на заседаниях Кабинета Министров Республики Узбекистан. На этих форумах, проводимых на высшем государственном уровне, обсуждаются назревшие проблемы развития малого и частного бизнеса, указываются узкие места и прогнозируются конкретные пути его дальнейшего развития. Много внимания проблемам развития малого и частного бизнеса уделяется учёными республики. Изучение опубликованных работ, число которых растёт с каждым днём показывает, что ученые в своих исследованиях стремятся выявить характер и причины негативных явлений и турбулентного состояния малого и частного бизнеса, дают глубокий критический самоанализ, выдвигают обоснованные предложения и научные рекомендации, направленные на его дальнейшее развитие. Разумеется, всякая научная статья для привлекательности и убедительности в той или иной мере содержит элементы научной фантазии, утрирования, а её автор претендует на правомерность своих суждений и выдвинутых предложений. Тем не менее, в каждой из них покоится реальное положение дел, не опровергаемые факты, аргументированные выводы о нашей действительности.

В условиях рыночной экономики малый и частный бизнес является важным фактором развития национальной экономики, увеличения ВВП и экономического роста. Малый бизнес и частное предпринимательство - это сфера приложения труда и источник доходов значительной части населения. Это наиболее гибкая часть рынка труда, поглощающая в условиях рыночной экономики, основную массу трудовых ресурсов невысокой квалификации и с недостаточным опытом, желающих иметь гибкий рабочий день. Часто только здесь могут найти работу женщины, молодые люди, впервые ищущие работу, имеющие невысокий уровень образования и трудового опыта.

Малое предпринимательство формирует особый социальный климат, сглаживая острые углы возможных противоречий между слоями общества, ока- 
зывает воздействия на развитие конкуренции, а значит на формирование конкурентных цен на товары, от чего выигрывают и потребители и общество в целом, способствует расширению услуг, предоставляемых в сферах здравоохранения и образования.

Малый и частный бизнес является потенциально эффективным средством развития деловых и предпринимательских навыков у населения, повышения степени его адаптированности к рыночным отношениям, позволяя гражданам стать собственниками не только своей рабочей силы, но и имущества, в том числе и производственного назначения. Он создает базу для формирования среднего класса - социального слоя, способного обеспечить прогрессивное развитие общества, заинтересованного в демократии и социальной стабильности.

Малый бизнес является важным фактором роста национального благосостояния, так как именно он является главным источником доходов не только значительной части людей, занятых в его сфере, но и членов их семей. Кроме всего этого малое предпринимательство даёт возможность человеку объединить в одно целое работу и личную жизнь, самореализоваться, проявить свои способности и таланты. Такой потенциал малого предпринимательства заставляет уделять серьёзное внимание его развитию в странах, формирующих социальную экономику. Не случайно Президент Республики Узбекистан И.А.Каримов уделил его развитию как важнейшему средству решения проблем занятости и преодоления негативных социальных последствий мирового финансовоэкономического кризиса. Предусматривает обеспечение занятости прежде всего за счет развития малого предпринимательства. «Думаю, - отмечает он, что нет необходимости еще раз повторять, какое значение придается развитию малого бизнеса и сферы услуг в нашей социально - экономической политике, хочу только еще раз обратить внимание, что мобильный характер бизнеса, его способность относительно легко приспосабливаться к изменениям конъектуры рынка и запросов потребителей, делает его незаменимым инструментом создания новых рабочих мест и повышения доходов населения в период мирового экономического кризиса» [1].

Именно возможность поддержания занятости за счёт развития экономической самодеятельности населения и мобилизации его предпринимательского потенциала делает малое предпринимательство одним из инструментов регулирования рынка труда, который позволяет стабилизировать занятость без значительных инвестиций со стороны государства.

Занятость представляется основным фактором обеспечения жизнедеятельности общества, преодоления бедности и повышения уровня жизни населения вне зависимости от уровня социально - экономического развития страны, наиболее действенным способом решения проблем обеспечения человека необходимыми средствами существования. Рост занятости и улучшение ее качества означает повышение конкурентоспособности национальной экономики на внутреннем и внешних рынках, увеличение общего объема и среднедушевого ВВП, улучшение уровня и качества жизни населения. В целом в ВВП стран Европейского Союза доля малого и среднего бизнеса превышает 80-90 \%. В Японии в этом секторе экономики работает почти 70-80 \% занятого населения 
страны, в странах ЕС - более 70\%. В США доля малого и среднего бизнеса в ВВП страны за сорок лет выросла с 10\% до 80\%. Этим странам удалось создать комплексную систему государственной поддержки развития малого и среднего бизнеса, основанную в первую очередь, на создании законодательной базы и надёжной системы защиты прав и интересов предпринимателей, их доступа к льготным долгосрочным кредитным ресурсам, на формировании льготного налогового режима, производственной, финансовой, социальной, рыночной инфраструктур, призванных, в конечном итоге, служить эффективному развитию этого сектора экономики. Принимаемые государством активные меры по поддержке предпринимательства в нашей стране, за все годы реформирования экономики, обеспечили поступательное развитие малого бизнеса как в республике в целом, так и в отдельных его регионах.

Таблица 1. Снижение доля ставки налогов субъектам малого и частного бизнеса [2]

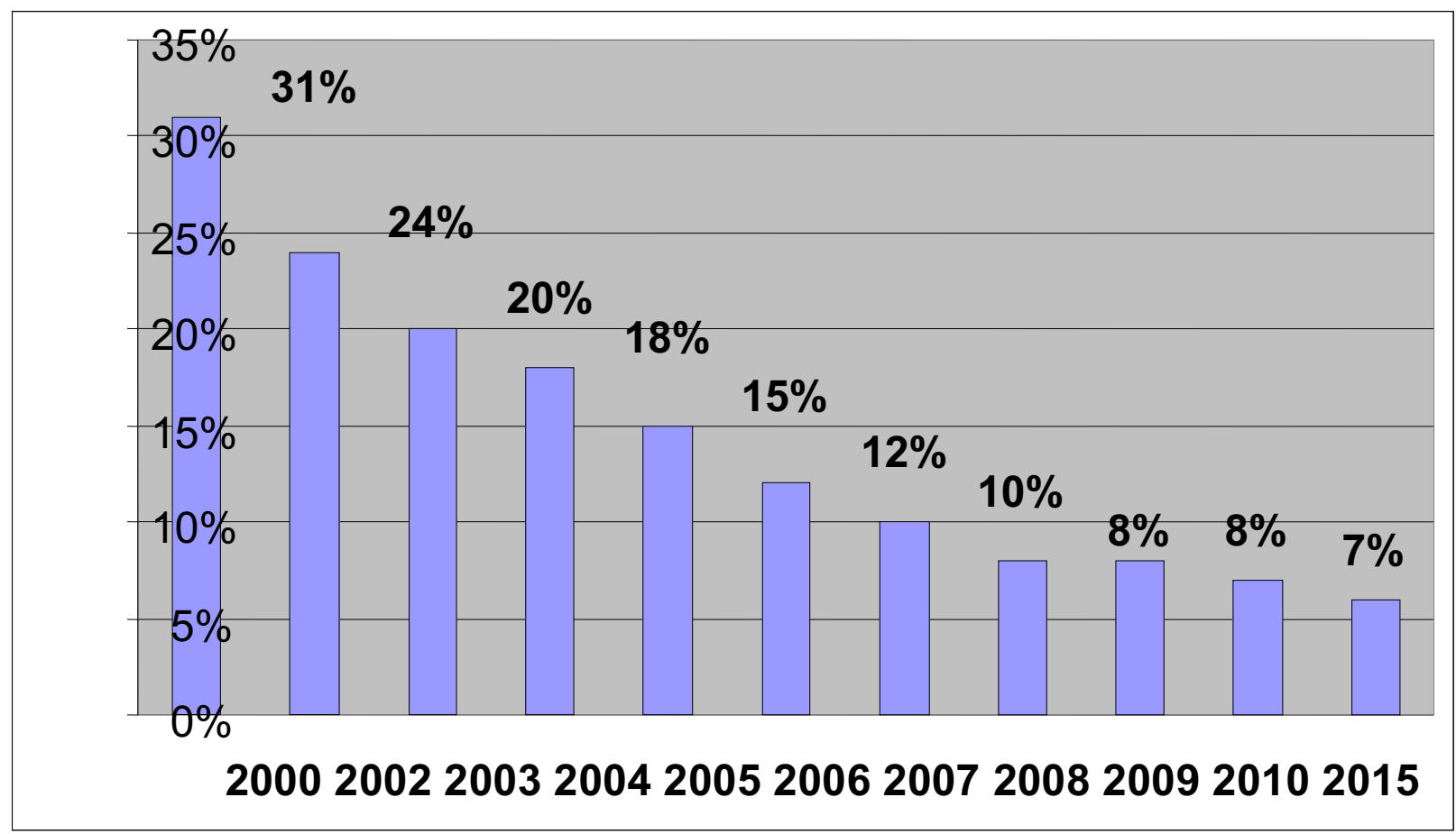

Для сохранения деловой активности и поддержки малого предпринимательства государство приняло ряд важных мер. Была продолжена работа по решительному сокращению бюрократических препятствий и либерализации национальной экономики, значительно снижены ставки по основным налогам. За период с 2000г. по 2015г. снизилась доля ставки налогов с 31 \% до 5 \% для малых предприятий (таблица-1).

В целом в 2015 году удельный вес малого бизнеса в производстве валового внутреннего продукта Узбекистана достиг $56,7 \%$, а общий уровень занятости в сфере малого и частного бизнеса составил 77\%, в том числе в индивидуальном секторе занято 6446,2 тыс. человек. А в малых предприятиях занято 17,6\% от общей численности занятых в экономике населения. Такая же тенденция за исследуемый период наблюдается и в Самаркандской области, где удельный вес малого бизнеса в ВВП в 2015 году возрос до 66,8\% [3]. 
В результате проведенного анализа в качестве наиболее значимой и положительной тенденции был выявлен общий рост занятости в сфере малого предпринимательства, в то время как в других секторах экономики занятость либо сохраняется на одном уровне в течение многих лет, либо сокращается. Именно за счёт роста занятости в малом предпринимательстве удалось избежать резкого всплеска безработицы в трудные годы мирового финансово-экономического кризиса [4].

Для дальнейшего увеличения количества рабочих мест на основе развития малого и частного бизнеса, как наиболее перспективного направления воздействия на рынок труда в условиях мирового финансово - экономического кризиса, необходимо обеспечить оптимальное взаимодействие государственных методов воздействия на экономику и рыночных механизмов саморегулирования с учетом объективных условий расширенного воспроизводства, соблюдения пропорций между подразделениями, секторами, отраслями национальной экономики. При этом отводимая роль сектору малого предпринимательство должна учитывать не только и не столько его возможности в наращивании экономического потенциала страны, но и его социальное предназначение - обеспечение трудозанятости населения, формирование класса собственников и др.

В условиях социально ориентированной рыночной экономики регулирование уровня жизни населения с целью согласования и реализации интересов всех социальных групп и слоев населения достигается не только на основе социальной защиты малообеспеченных и не имущих членов общества. В этих же целях государство принимает различные меры по сглаживанию резких колебаний в уровне доходов на основе сдерживания роста доходов предпринимателей. Понятно, что по мере развития рыночных отношений и повышения роли предпринимательской деятельности в создании ВВП и подъеме производства, доходы от этой деятельности будут возрастать как в абсолютном, так и в относительном измерении. Государство, в целях недопущения глубокой дифференциации в пользу лиц, занимающихся предпринимательской деятельностью и собственников средств производства, через систему прогрессивных налогов в определенной мере выравнивает доходы и сглаживает, тем самым, чрезмерную дифференциацию населения по уровню жизни. Выступая на заседании Кабинета Министров Республики Узбекистан, посвященное итогам социально-экономического развития страны в 2015 году и важнейшим приоратам экономической программы на 2016 год глава нашего государства отметил, что «... в Узбекистане, в отличие от других стран на постсоветском пространстве, отсутствует резкое расслоение населения по уровню доходов. При этом следует учитывать и то важное обстоятельство, что недопущение явной поляризации общества по уровню доходов не только решает проблемы обеспечения социальной стабильности в обществе, но и выступает важнейшим фактором повышения эффективности использования всех имеющихся ресурсов.

\section{Список используемых источников:}

1. Доклад Президента Республики Узбекистан И. Каримова на заседании Кабинета Министров, посвященном итогам социально-экономического развития страны в 2015 году и важнейшим 
приоритетам направлениям экономической программы на 2016 году // Газ. “Народное слово” от 16 января, 2016.

2. Основные показатели социально-экономического развития Республики Узбекистан. www.stat.uz.C.9.

3. Статистический сборник управления статистики Самаркандской области. Самарканд: 2015.С.7-8.

4. Гулямов С.С. вище-президент АН РУз в связи с отсутствием данных за 2016 г. были использованы данные за 20152.

5. Гейтс Б. Бизнес со скоростью мысли. М.: Изд-во ЭКСМО- Пресс, 2001 г. 345c.

6. Глухов В.В., Коробко С.Б., Маринина Т.В. Экономика знаний. СПБ.: Питер, 2003. 528c.

7. Доугерти К. Введение в эконометрику. М.: Инфра-М, 1999. $576 c$.

8. URL: www.stat.uz

(C) 2016, Уринбаева Ю.П.

Перспективы повышения уровня жизни населения на основе развития малого и частного бизнеса
(C) 2016, Urinbayeva Yu.P.

Prospects for raising living standards through the development of small and private business 